\title{
Sandwich-Type Electrochemical Paper-Based Immunosensor for Claudin 7 and CD81 Dual Determination on Extracellular Vesicles from Breast Cancer Patients
}

Francisco G. Ortega, Matías D. Regiart,* Alba Rodríguez-Martínez, Diego de Miguel-Pérez, María J. Serrano, José A. Lorente, Gonzalo Tortella, Olga Rubilar, Karim Sapag, Mauro Bertotti, and Martín A. Fernández-Baldo*

Cite This: https://dx.doi.org/10.1021/acs.analchem.0c04180

Read Online

ACCESS | Lلll Metrics \& More | 回 Article Recommendations | st Supporting Information

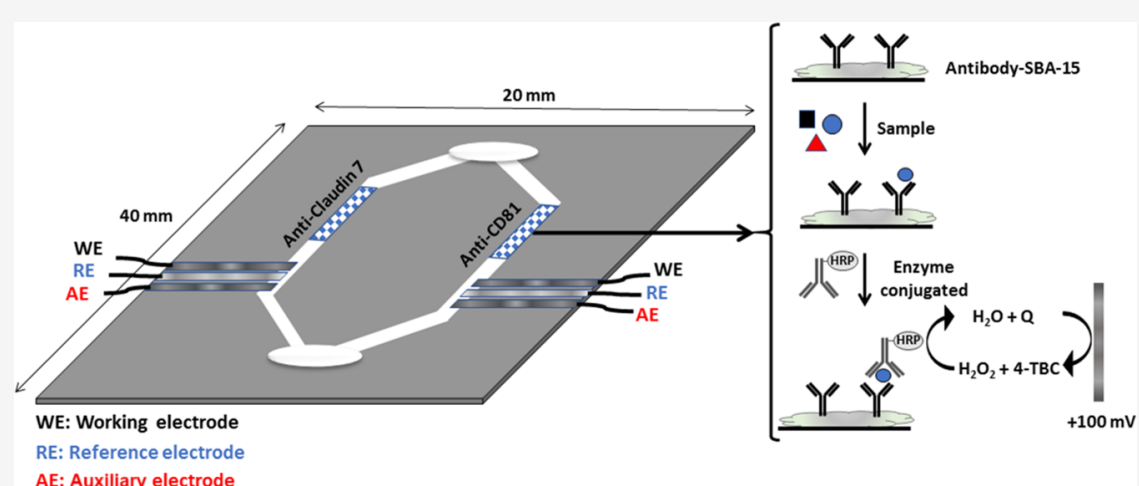

ABSTRACT: This study is focused on identifying novel epithelial markers in circulating extracellular vesicles (EVs) through the development of a dual sandwich-type electrochemical paper-based immunosensor for Claudin 7 and CD81 determination, as well as its validation in breast cancer (BC) patients. This immunosensor allows for rapid, sensitive, and label-free detection of these two

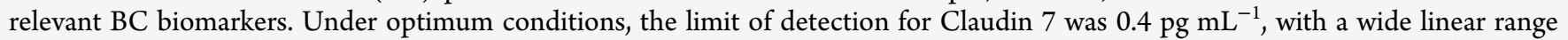
of 2 to $1000 \mathrm{pg} \mathrm{mL}^{-1}$, while for CD81, the limit of detection was $3 \mathrm{pg} \mathrm{mL}^{-1}$, with a wide linear range of 0.01 to $10 \mathrm{ng} \mathrm{mL}$. Finally, we validated Claudin 7 and CD81 determination in EVs from 60 BC patients and 20 healthy volunteers, reporting higher diagnostic accuracy than the one observed with classical diagnostic markers. This analysis provides a low-cost, specific, versatile, and userfriendly strategy as a robust and reliable tool for early BC diagnosis.

\section{INTRODUCTION}

Breast cancer $(\mathrm{BC})$ is the most common cancer disease among females all over the world. $\mathrm{BC}$ is the principal cause of cancerrelated death in women in less developed countries and the second leading cause in developed ones. ${ }^{1}$ Clinical studies showed that early diagnosis followed by suitable treatments significantly improved the survival rates. ${ }^{2}$ Mammography is the preferred method for BC detection; however, this method could be less effective in young women with dense breasts. ${ }^{3}$ Blood-based screenings are cost-effective applications for BC diagnosis and, unfortunately, a reliable blood marker for accurate diagnosis at early stages is not available yet. ${ }^{4}$ Detection of circulating proteins such as carcinoembryonic antigen (CEA) or cancer antigen 15.3 (CA 15-3) is actually being employed without proper results in early stages. Recently, circulating tumor cells, free DNA, and extracellular vesicles (EVs) have been demonstrated to be very specific markers for diagnosis, characterization, and monitoring of cancer disease. ${ }^{5}$ EVs present several advantages compared to other liquid biopsy components. Mainly, EVs are released in early stages of cancer and their structure works as a capsule that protects the molecular and proteomic cargo. Moreover, EV isolation is a relatively fast, easy, and robust method. ${ }^{6}$

EVs are lipid-bilayered vesicles released by a variety of mammalian cells. ${ }^{7}$ EVs enclose different types of membraneassociated proteins, and some of them are specific to the cell where they were produced. ${ }^{7}$ Epithelial cancer cells have increased EV release rates compared to healthy epithelial cells due to tumor hypoxia, ${ }^{8}$ endo-lysosomal trafficking disruption, and cellular stress. ${ }^{9}$ As a consequence, the percentage of

Received: October 5, 2020

Accepted: November 25, 2020 
epithelial EVs isolated in plasma from epithelial cancer patients is higher. Unfortunately, epithelial EVs represent a very small fraction of the total of EVs found in peripheral blood and, for this reason, one of the main challenges in measuring these proteins is the development of sensitive and specific analytical methods. ${ }^{10}$

Because of outstanding features such as superior selectivity and sensitivity compared to standard enzyme-linked immunosorbent assay (ELISA) tests, electrochemical immunosensors have been quickly adopted for the detection of some cancer markers. $^{11-15}$ Specifically, in the last years, paper-based immunosensors have received considerable attention from the scientific community because of the advantages of low cost, biocompatibility, ease of storage, portability, and the possibility of performing chemical analysis using capillary flow without the need for external pumps. ${ }^{16}$ Electrochemical detection is quite promising because of its compatibility with microfabrication techniques, adjustable selectivity, low levels of detectability, and portability, mainly when used in combination with battery-powered potentiostats. ${ }^{17}$ Moreover, different techniques can be explored to fabricate the electrodes on paper platforms, including sputtering, screen-printing, stencilprinting, inkjet-printing, laser scribing, microwire placement, and direct drawing, among others. ${ }^{13,18-20}$

Besides, among the least expensive of these devices are the recently introduced electrochemical microfluidic paper-based analytical devices ( $\mu$ PADs).$^{21-24} \mu$ PADs have the potential to be good alternatives for point-of-care testing over traditional glass and polymer-based devices because they are easy to use, are inexpensive, require small volumes of reagents and sample, provide rapid analysis, are disposable, can be made from renewable substrate materials, and are portable. ${ }^{21-23}$ Channel fabrication is a crucial step in the development of an effective $\mu \mathrm{PAD}$. The fabrication of a hydrophobic barrier is a common method to define channels in paper devices, and several techniques have been presented in the literature, such as photolithography, wax printing, screen printing, and inkjet printing, among others. ${ }^{21-24}$

Recently, different kinds of materials have been employed for the fabrication of electrodes and channel surface modifications of $\mu \mathrm{PAD}$ for biomolecule immobilization. ${ }^{14,24,25}$ Accordingly, conductive metal nanoparticles and carbon-based materials such as carbon nanotubes or graphene are commonly used. Graphene is a carbon allotrope that has attracted the attention of the scientific community in recent times. This material exhibits excellent mechanical, thermal, and electrical properties and can be used to make electronic devices for a variety of applications, including sensors. ${ }^{26}$ As for the modification of the inner channel surface, SBA-15 is an ordered mesoporous silica that has attracted intense interest because of its large surface area, well-defined pore structure, inertness, nontoxicity, high biocompatibility, and thermal and hydrothermal stability, which make this material an excellent immobilization platform for biomolecules. ${ }^{27}$

A variety of $\mu \mathrm{PAD}$ designs have been developed for some cancer biomarker applications. Sun and co-workers (2018) reported a novel rotational paper-based analytical device to implement multistep electrochemiluminescence immunoassays. ${ }^{28}$ This method was applied to CEA and prostate-specific antigen (PSA) detection. In addition, the rotational valves are reusable and the response time can be shortened to a few seconds, conferring significant advantages to the device in multistep operations. Wang et al. $(2018)^{29}$ presented a novel dual-mode cytosensor based on polyhedral AuPd alloy nanoparticles and three-dimensional reduced graphene oxide (rGO) constructed for highly sensitive detection of MCF-7 cells. This paper-based dual-mode cytosensor provided a reliable pathway for sensitive detection of cancer cells in clinical applications. Wei et al. (2018) developed a low-cost, label-free, and highly sensitive and selective electrochemical aptamer sensor to detect PSA in serum samples using a disposable $\mu \mathrm{PAD} .{ }^{30}$ The authors proposed this method as a new platform for sensitive and point-of-care diagnosis of prostate cancer.

In this work, a high throughput proteomic analysis of EVs isolated from seven $\mathrm{BC}$ patients and five healthy donors was performed by reverse phase proteomic array (RPPA) technology in order to identify an epithelial marker candidate to be validated in a larger cohort of patient and healthy volunteers. After the identification of Claudin 7 as an epithelial marker and CD81 as housekeeping, we developed a dual sandwich-type electrochemical paper-based immunosensor for both markers. Finally, the novel biomarker Claudin 7 was demonstrated to be useful for diagnosis of early stages of $\mathrm{BC}$ from results of experiments carried out in circulating EVs from a cohort of 60 early BC patients and 20 healthy donors. To the best of our knowledge, no study based on the present analytical methodology for $\mathrm{BC}$ diagnosis on $\mathrm{EV}$ samples has been reported.

\section{EXPERIMENTAL SECTION}

All materials, reagents, apparatus, and patients characteristics are shown in the Supporting Information 1.

EV Isolation and Sample Preparation. EVs were obtained from plasma of BC and healthy donors. Plasma was obtained from freshly drawn blood using separate plasma tubes. Aliquots of each plasma sample were deep-frozen at storage using liquid nitrogen. All plasma samples were transported to the laboratory on dry ice within $24 \mathrm{~h}$.

EVs were isolated with qEV columns (IZON, New Zealand) by size exclusion chromatography (SEC), according to the manufacturer's recommended protocol. Eluted fractions enriched in EVs were concentrated by Nanosep centrifugal devices with $300 \mathrm{kD}$ membranes (Pall Corporation, USA). Then, the obtained EVs were lysed with $50 \mu \mathrm{L}$ of lysis buffer containing 1\% Triton X-100, $50 \mathrm{mmol} \mathrm{L}^{-1}$ Hepes pH 7.40, 150 mmol L ${ }^{-1} \mathrm{NaCl}, 1.5 \mathrm{mmol} \mathrm{L}^{-1} \mathrm{MgCl}_{2}, 1 \mathrm{mmol} \mathrm{L}^{-1}$ EGTA, 100 mmol L $\mathrm{L}^{-1} \mathrm{NaF}, 10 \mathrm{mmol} \mathrm{L} \mathrm{L}^{-1} \mathrm{Na}$ pyruvate, $1 \mathrm{mmol} \mathrm{\textrm {L } ^ { - 1 }}$ $\mathrm{Na}_{3} \mathrm{VO}_{4}, 10 \%$ glycerol, and a cocktail of protease and phosphatase inhibitors (Roche Diagnostics, Mannheim, Germany). Samples were kept at $-80^{\circ} \mathrm{C}$ until future analysis.

Characterization of Plasma-Isolated EVs. Isolated EVs were characterized following the International Society of Extracellular Vesicles (ISEV) recommendations: ${ }^{31}$ identification of specific EVs by specific markers (CD81 and HSC70) and the lack of a negative marker (GM130) by western blot $(\mathrm{WB}){ }^{32}$ single vesicle analysis by nanoparticle tracking analysis (NTA), and transmission electron microscopy (TEM). The detailed procedure is shown in the Supporting Information 2.

Candidate Marker's Identification by RPPA. EV samples obtained from BC patients $(n=7)$ and healthy donors $(n=5)$ were submitted to the proteomic facilities of the MD Anderson Cancer Institute (Texas, USA), following the facility requirements in order to identify a candidate epithelial marker to be validated as a diagnostic marker of early BC. Samples were analyzed in a single slide, according to pre- 


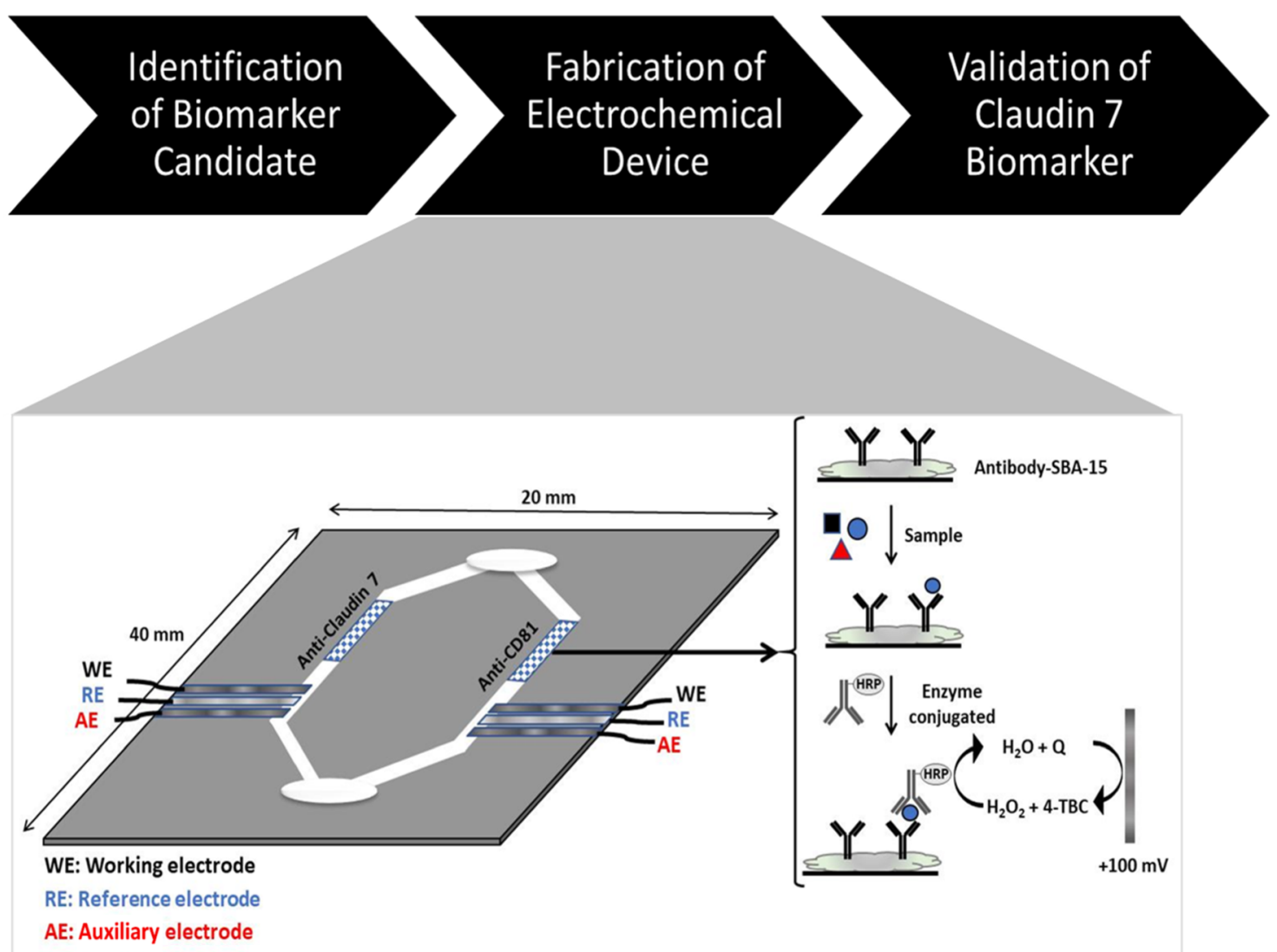

Figure 1. Schematic representation of the present study which includes the following: (i) biomarker identification, (ii) design of the electrochemical paper-based immunosensor surface modification, and (iii) validation of biomarkers with the designed immunosensor.

established protocols. ${ }^{33}$ RPPA procedures are summarized in the Supporting Information 3.

ELISA Analysis. ELISA determinations were performed according to specific supplier's recommendations for Claudin 7 (LSBIO, USA) and CD81 (Biorbyt, UK).

Electrochemical Device Fabrication. A dual electrochemical immunosensor device was fabricated to validate the biomarker candidate. It consists of a microfluidic paper-based device, where the channels were fabricated by wax printing, while the electrodes were printed with GO and silver ink.

The GO suspension was obtained from graphite powder according to the Hummer's method with some modifications, ${ }^{34}$ and the GO ink was fabricated according to a previously reported method including several modifications. ${ }^{26}$ Brief descriptions of these procedures are summarized in the Supporting Information 4 and 5.

The fabrication of the electrochemical paper-based device was performed according to a previously reported method, ${ }^{20}$ with slight modifications. First, two electrochemical cells (containing working, auxiliary, and reference electrodes) were printed in one side of a $20 \times 40 \mathrm{~mm}$ Whatman paper \# 1 (one electrochemical cell for each channel) (Figure 1). The working and auxiliary electrodes were printed using the GO ink over a silver ink track. The Ag-pseudo reference electrode was printed using silver ink. The layout of the device was prepared using the Corel Draw software. The electrodes consisted of squares with $2 \mathrm{~mm}$ side, and the electrode connections were made by painting with silver ink in order to ensure the electrical contact with the electrochemical workstation. The electrochemical reduction of $\mathrm{GO}$ to $\mathrm{rGO}$ was performed according to a previously reported method. ${ }^{35}$ Briefly, the electrode was biased at a fixed potential $(-1.4$ $\mathrm{V})$ in $0.1 \mathrm{~mol} \mathrm{~L}^{-1}$ PBS for $900 \mathrm{~s}$. Then, the rGO modified electrode was washed with Milli-Q water, followed by a dry step with $\mathrm{N}_{2}$.

The $\mu \mathrm{PAD}$ channels were fabricated on the same side of the paper by a wax printing technique. ${ }^{19}$ The channels were designed using Corel Draw, and the hydrophobic barriers were delimited by wax over the previously printed electrodes. The device consists of one inset and one outlet connected by two parallel channels (each used to detect one biomarker) with a 3 $\mathrm{mm}$ width and $20 \mathrm{~mm}$ length. After printing, the paper was heated at $90{ }^{\circ} \mathrm{C}$ for $5 \mathrm{~min}$ to achieve homogenization of the hydrophobic walls. Then, in order to generate aldehyde groups in the paper for the next step (modification of the paper channel surface), its surface was treated with $\mathrm{O}_{2}$ plasma for 1 min. ${ }^{36}$

Modification of the Paper Channel Surface. SBA- $15^{37}$ and amino-functionalized SBA- $15^{38}$ were synthesized according to previously reported procedures (Supporting Information 6). The synthetized amino-functionalized SBA-15 at a $1.5 \mathrm{mg}$ $\mathrm{mL}^{-1}$ concentration was immobilized on the paper channel surface (immobilization zone) through covalent binding between aldehyde groups on the paper and the amino groups of the SBA-15 microparticles, as shown in Figure 1. First, 10 $\mu \mathrm{L}$ of $5 \%$ glutaraldehyde in $0.1 \mathrm{~mol} \mathrm{~L}^{-1}$ phosphate buffer $\mathrm{pH}$ 8.00 was placed in the channel for $2 \mathrm{~h}$ at room temperature. In this step, the amino groups present in the SBA-15 surface react with aldehyde groups of glutaraldehyde, leaving aldehyde groups free to interact with the amino groups present in the 
a)

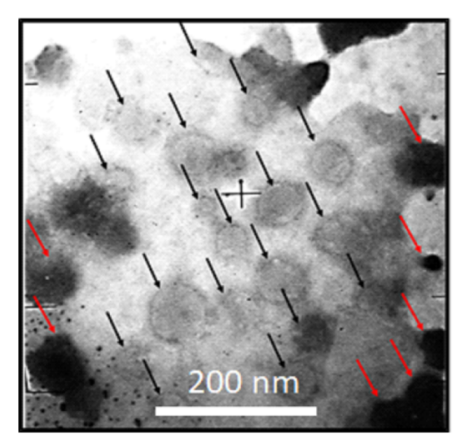

b)

NTA analysis

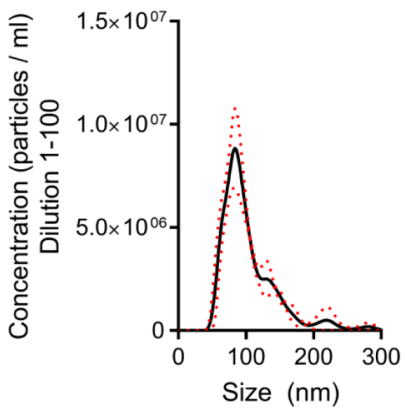

c)

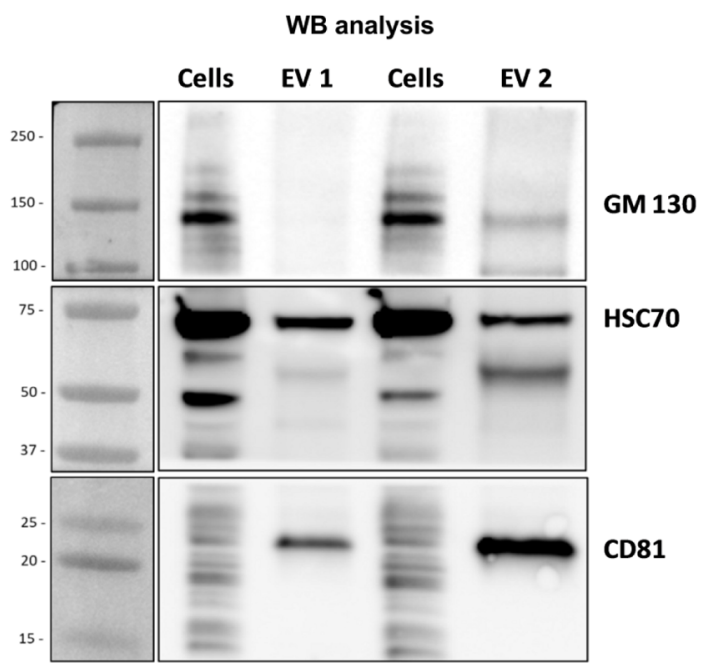

Figure 2. TEM image of isolated EVs from patients after purification via SEC. Red arrows show lipoprotein contamination, while black arrows depict EVs (a). NTA of isolated EVs shows particles with $105 \mathrm{~nm}$ of size average (mode $=82 \mathrm{~nm}$ ), SD is represented as red dot line in the graphic (b). Western blot image from cell controls and EV lysates (c).

capture antibodies. Later, $10 \mu \mathrm{g} \mathrm{mL}^{-1}$ anti-Claudin 7 and antiCD81 solutions prepared in $0.1 \mathrm{~mol} \mathrm{~L}^{-1}$ PBS were incubated in their respective immobilization zones in the channel for $12 \mathrm{~h}$ at $4{ }^{\circ} \mathrm{C}$. The platform generated by such an immobilization procedure was shown to be stable at least for 1 month at $4{ }^{\circ} \mathrm{C}$.

Analytical Procedure for Claudin 7 and CD81 Biomarker Determination. The $\mu \mathrm{PAD}$ was washed with $0.1 \mathrm{~mol} \mathrm{~L} \mathrm{~L}^{-1} \mathrm{PBS}$, followed by a blocking treatment with $1 \%$ BSA for $30 \mathrm{~min}$ to avoid the nonspecific binding on the free sites. After a washing step with $0.1 \mathrm{~mol} \mathrm{~L}^{-1} \mathrm{PBS}, 10 \mu \mathrm{L}$ of a previously treated sample was added and incubated in a humid chamber for $5 \mathrm{~min}$, followed by a washing step. In this step, Claudin 7 and CD81 present in the sample are immunologically recognized by the antibodies immobilized in the respective channel. Later, a new washing step with $0.1 \mathrm{~mol}$ $\mathrm{L}^{-1}$ PBS was carried out in order to eliminate the sample excess, followed by the addition of $10 \mu \mathrm{L} \mathrm{HRP-anti-Claudin} 7$ and HRP-anti-CD81 mix for $5 \mathrm{~min}$ and a further washing step. Finally, the substrate solution $\left(1 \mathrm{mmol} \mathrm{L}{ }^{-1} \mathrm{H}_{2} \mathrm{O}_{2}+1 \mathrm{mmol}\right.$ $\mathrm{L}^{-1}$ 4-TBC in $0.1 \mathrm{~mol} \mathrm{~L}^{-1}$ phosphate-citrate buffer $\mathrm{pH} 5.00$ ) was added. $\mathrm{HRP}$ catalyzes the $\mathrm{H}_{2} \mathrm{O}_{2}$ chemical reduction to $\mathrm{H}_{2} \mathrm{O}$, with the subsequent oxidation of catechol $\left(\mathrm{H}_{2} \mathrm{Q}\right)$ to $p$ benzoquinone $(\mathrm{Q})$, which is detected by amperometry at +100 $\mathrm{mV}$ on the rGO working electrode (Figure 1).

Statistical Analysis. Statistic differences between BC patients and healthy controls were determined by $t$-test. The linear correlation between the two variables was measured by the Pearson correlation coefficient. The distribution between categorical variables was assessed by the $\chi^{2}$ test. $P$-values less than 0.05 were considered statistically significant. Areas under receiver operating characteristic (ROC) curves were employed to assess the specificity and sensitivity.

\section{RESULTS AND DISCUSSION}

Identification of Claudin 7 in Circulating EVs in the Early Stage of BC Patients. EVs obtained from two healthy donors were characterized according to the International Society of Extracellular Vesicles (ISEV) recommendations. ${ }^{31}$ TEM analysis reported vesicles with typical morphology and size between 50 and $150 \mathrm{~nm}$. NTA (Nanosight) showed particles with $105 \mathrm{~nm}$ of size average $($ mode $=82 \mathrm{~nm})$. Finally, the WB analysis displayed HSC70 and CD81 specific expression on isolated EVs and the absence of GM130 (Figure 2).

To identify biomarkers in circulating EVs of early BCdiagnosed patient, EVs were isolated from plasma of healthy control subjects $(n=5)$ and patients with BC (stages II and III; $n=7$ ) and subsequently analyzed by RPPA technology. Among differentially expressed proteins, 72 were upregulated and 113 were downregulated in patients with BC (Figure 3). Claudin 7 was the most differentially expressed protein in the BC patient group $\left(p=9.63 \times 10^{-5}\right)$, considering the epithelial 
a)

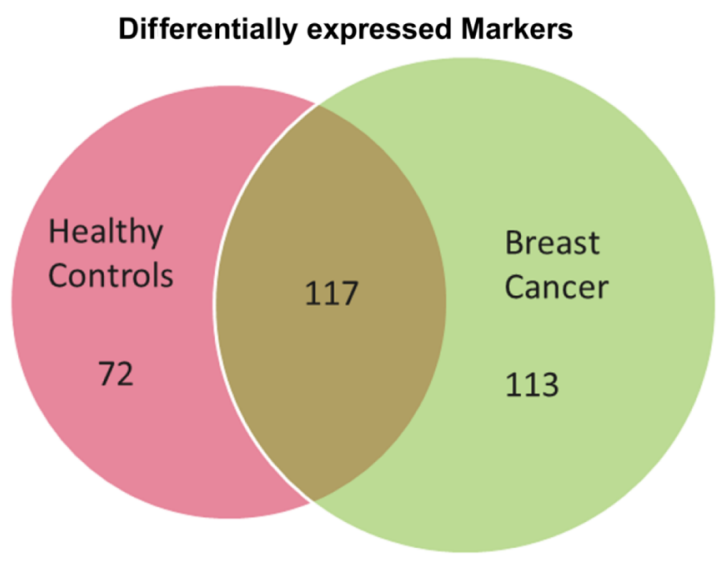

b)

Epithelial Marker Levels

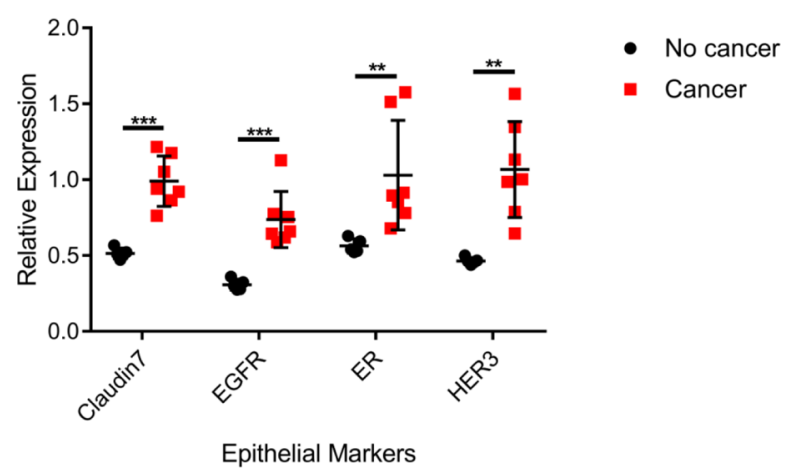

Figure 3. VENN diagram summarizing RPPA analysis, where 72 proteins were enriched in healthy control and 113 enriched in EVs from BC patients (a). Box plot showing epithelial markers significantly highly expressed in patients (Claudin $7 p$ value $=9.6 \times$ $10^{-5}$, epithermal growth factor receptor $\left(\right.$ EGFR) $p$ value $=2.4 \times 10^{-4}$, estrogen receptor $(\mathrm{ER}) p$ value $=4.4 \times 10^{-3}$, HER3 $p$ value $=6.1 \times$ $\left.10^{-4}\right)(\mathrm{b})$. Values represent concentration related to the average of all samples.

upregulated ones. Claudin 7 is an epithelial-specific protein that belongs to epithelial tight junctions and plays an important role in maintaining cell polarity and regulating cell permeability. According to recent reports, Claudin 7 is overexpressed in most BC primary tissues, independent of $\mathrm{BC}$ subtypes and clinical or pathological variables. According to our findings and bibliographic information about Claudin 7, we decided to employ this protein as a candidate biomarker in EVs.

After choosing the candidate biomarker, we focused on testing CD81 as a housekeeping in EVs. CD81 is a specific marker for EVs, but unfortunately, it is not expressed in 100\% of plasma EVs. To test whether this tetraspanin is suitable to correct variations in loading, CD81 was analyzed by ELISA in all samples submitted to RPPA. Then, CD81 values were compared with the median obtained by RPPA for each sample and an excellent correlation between both parameters was found (Pearson $r=0.9991, p<0.0001$ ) (Supporting Information 7), demonstrating that CD81 is a suitable protein for the normalization of Claudin 7 expression in EVs.

Characterization of Synthesized SBA-15. SBA-15 was morphologically characterized by scanning electron microscopy (SEM) and TEM (Figure 4). SBA-15 particles elongated with a $1.0 \pm 0.2 \mu \mathrm{m}$ length and $400 \pm 50 \mathrm{~nm}$ width can be noticed in the SEM micrograph of the paper modified with
SBA-15 (Figure 4a). The TEM micrograph of SBA-15 shows the typical hexagonal structure and pore homogeneity of this mesoporous material (Figure $4 \mathrm{~b}$ ).

The SBA-15 $\mathrm{N}_{2}$ adsorption-desorption isotherm is shown in Figure $4 c$, and the type IV isotherm with a $\mathrm{H} 1$ type hysteresis is typical of mesoposorous materials with welldefined cylinder-like pore channels and with uniform pore size. The inset of Figure $4 \mathrm{c}$ shows that the SBA-15 pore size distribution is narrow ( $8 \mathrm{~nm}$ width).

SBA-15 textural properties were as follows: $S_{\mathrm{BET}}: 890 \mathrm{~m}^{2} \mathrm{~g}^{-1}$, $V_{\mu \mathrm{P}}: 0.05 \mathrm{~cm}^{3} \mathrm{~g}^{-1}, V_{\mathrm{PMP}}: 0.55 \mathrm{~cm}^{3} \mathrm{~g}^{-1}$, and $V_{\mathrm{TP}}: 1.12 \mathrm{~cm}^{3} \mathrm{~g}^{-1}$. A Fourier-transform infrared (FTIR) study was performed to confirm the SBA-15 amino functionalization, and results presented in Figure 4d show the changes in the $\mathrm{Si}-\mathrm{O}-\mathrm{Si}$ $\left(460 \mathrm{~cm}^{-1}\right), \mathrm{N}-\mathrm{H}\left(690 \mathrm{~cm}^{-1}\right), \mathrm{Si}-\mathrm{O}-\mathrm{Si}\left(800 \mathrm{~cm}^{-1}\right), \mathrm{Si}-\mathrm{OH}$ $\left(965 \mathrm{~cm}^{-1}\right), \mathrm{C}-\mathrm{N}, \mathrm{Si}-\mathrm{O}-\mathrm{Si}, \mathrm{Si}-\mathrm{CH}_{2}-\mathrm{R}\left(1220 \mathrm{~cm}^{-1}\right), \mathrm{NH}_{3}^{+}$ $\left(1555 \mathrm{~cm}^{-1}\right), \mathrm{H}-\mathrm{O}-\mathrm{H}\left(1645 \mathrm{~cm}^{-1}\right)$, and $-\mathrm{OH}\left(3500 \mathrm{~cm}^{-1}\right)$ peaks.

Characterization of rGO Electrodes. The morphological characterization of the rGO electrode surface was carried out by SEM. Figure 5 a shows a uniform rGO spread over the paper surface, indicating that the ink suspension is homogeneous. Figure $5 \mathrm{~b}$ shows the energy dispersive spectra of (I) GO and (II) rGO, and the decrease in the oxygen amount in the rGO confirms the reduction of oxygenated functional moieties.

The electrochemical behavior of the rGO electrode was examined to ensure its performance. Catechol was used as a probe because the electron-transfer process associated with this molecule is fast and well-known. Figure 5c shows a cyclic voltammogram recorded in $1 \mathrm{mmol} \mathrm{L}^{-1}$ catechol $+0.1 \mathrm{~mol} \mathrm{~L}^{-1}$ phosphate-citrate buffer $\mathrm{pH} 5.00$ and the typical reversible process corresponding to the anodic oxidation of catechol to $p$ benzoquinone at $+414 \mathrm{mV}$, and the subsequent cathodic reduction at $+334 \mathrm{mV}$ confirms the excellent electrical conductivity of rGO. Moreover, a study of the influence of the scan rate on the peak current was performed in the 25-200 $\mathrm{mV} \mathrm{s}^{-1}$ range (Figure $5 \mathrm{~d}$ ). The linear relationship between the peak current values and the square root of the scan rate (inset of Figure 5d) demonstrates that the catechol overall electrontransfer process over the rGO surface is mass transportcontrolled.

The electrochemical surface area was calculated by the Randles-Sevcik equation. ${ }^{39}$

$$
I_{\mathrm{p}}=2.69 \times 10^{5} A D^{1 / 2} n^{3 / 2} \nu^{1 / 2} \mathrm{C}
$$

where $I_{\mathrm{p}}$ is the peak current in amps, $A$ is the electrode area in $\mathrm{cm}^{2}, D$ is the diffusion coefficient in $\mathrm{cm}^{2} \mathrm{~s}^{-1}, n$ is the number of electrons transferred in the electron transfer process, $\nu$ is the scan rate in $\mathrm{V} \mathrm{s}^{-1}$, and $C$ is the concentration in $\mathrm{mol} \mathrm{L}^{-1}$, and the value was found to be $0.239 \mathrm{~cm}^{2}$.

Optimization of Experimental Parameters. A systematic investigation was performed to optimize the experimental parameters that affect the biomarker determination in real samples. This was accomplished by using a $500 \mathrm{pg} \mathrm{mL}^{-1}$ Claudin 7 solution, and the following parameters were studied: $\mathrm{pH}$ and concentration of antibody, SBA-15, and GO ink (Supporting Information 8).

Analytical Performance for Claudin 7 and CD81 Biomarker Determination. Claudin 7 and CD81 biomarker determination was carried out under the optimized conditions using the dual electrochemical paper immunosensor, and the results were compared with those obtained with the 

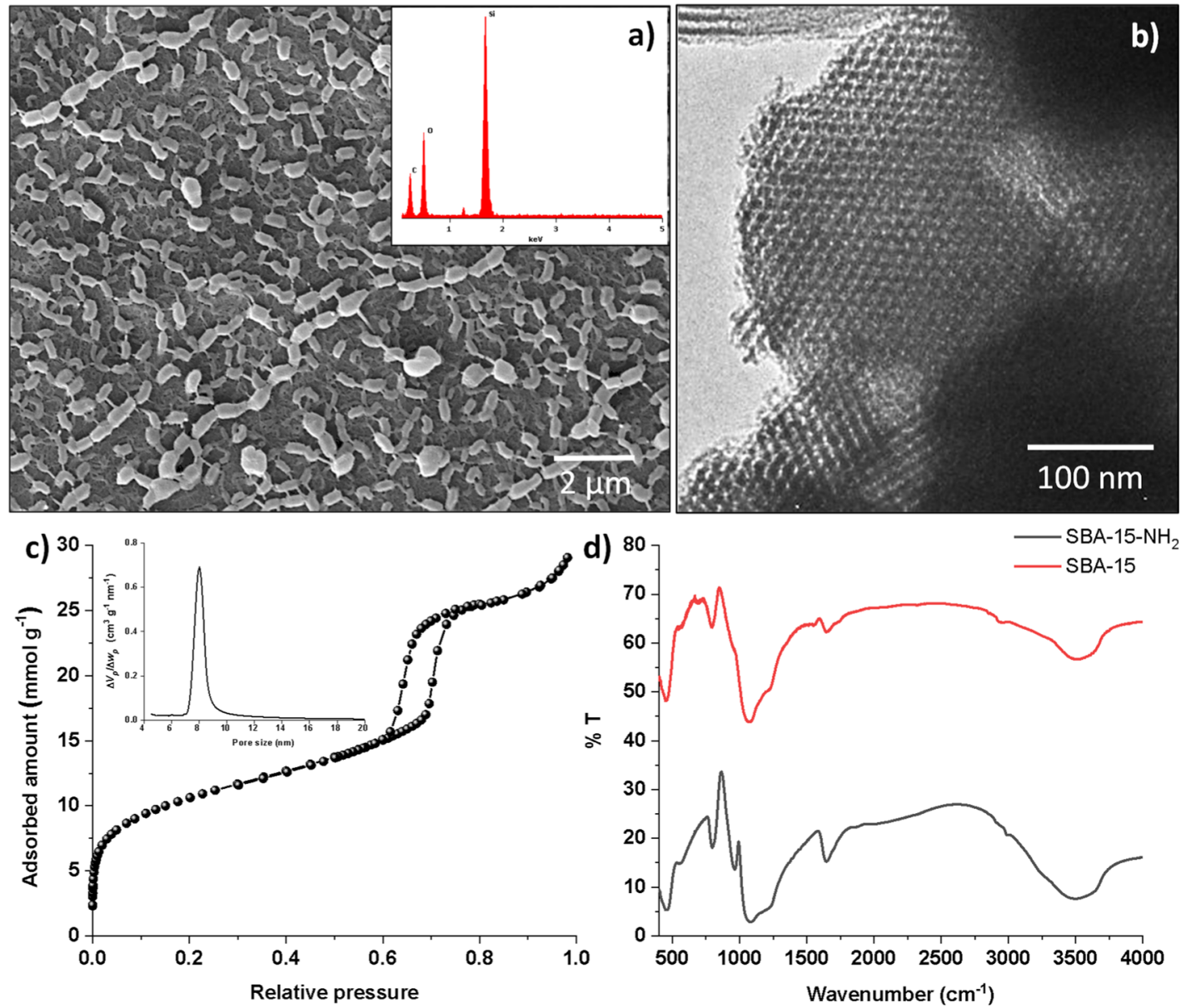

Figure 4. SEM (a) and TEM (b) images of the SBA-15. $\mathrm{N}_{2}$ adsorption-desorption isotherm of SBA-15 at $77 \mathrm{~K}$ (c). FTIR spectra of SBA-15 and amino functionalized SBA-15 (d).

commercial ELISA kit for each BC biomarker. The Claudin 7 calibration curve was prepared using standard solutions, with concentrations ranging from 0.5 to $1200 \mathrm{pg} \mathrm{mL}^{-1}$, and a linear relationship was observed between 2 and $1000 \mathrm{pg} \mathrm{mL}^{-1}$. The linear regression equation was $I(\mathrm{nA})=6.69+0.24 C_{\text {Claudin } 7}$, with a linear regression coefficient $R=0.998$ (Supporting Information 9). The coefficient of variation (CV \%) for the determination of $500 \mathrm{pg} \mathrm{mL}^{-1}$ Claudin 7 was $3.75 \%(n=5)$. A similar calibration plot was obtained for Claudin 7 by using the ELISA kit, and the linear regression equation was $A=0.17+$ $0.01 C_{\text {Claudin } 7,} R=0.996$, and the $\mathrm{CV} \%$ was $7.32 \%$. The correlation between the results obtained by using the electrochemical paper immunosensor and the reference method (ELISA) was also assessed in EV samples of patients in a double-blinded experiment, which was performed by two independent researchers. Figure 6a shows the straight line with a slope of 1.01, indicating good correspondence between both methods. The limit of detection (LOD) values for the $\mu \mathrm{PAD}$ and the commercial ELISA kit were 0.4 and $3.9 \mathrm{pg} \mathrm{mL}^{-1}$, respectively. The precision of the developed method was evaluated using Claudin 7 standards. The within-assay precision was tested by five measurements on the same day. These analyses were repeated for 3 consecutive days to estimate the between-assay precision. The developed immunosensor showed good precision; the $\mathrm{CV}$ within-assay and between-assay values were below 3.96 and $6.14 \%$, respectively.

The CD81 calibration plot was prepared using standard solutions in the concentration ranging from 0.005 to $10 \mathrm{ng}$
$\mathrm{mL}^{-1}$. A linear relationship was observed between 0.01 and 10 $\mathrm{ng} \mathrm{mL} \mathrm{m}^{-1}$. The linear regression equation was $I(\mathrm{nA})=5.40+$ $23.78 C_{\mathrm{CD} 81}$, with a linear regression coefficient $R=0.998$ (Supporting Information 9). The CV \% for the determination of $5 \mathrm{ng} \mathrm{mL} \mathrm{mL}^{-1} \mathrm{CD} 81$ was $3.66 \%(n=5)$. Parallel measurements with the ELISA test yielded a calibration plot whose linear regression equation was $A=0.08+0.26 C_{\mathrm{CD} 81}, R=0.997$, and the $\mathrm{CV} \%$ was $6.65 \%$. To validate the proposed immunosensor method, a comparison was performed with the results of CD81 determinations obtained with the ELISA test. The slope close to 1 (Figure 6b) demonstrated a good correspondence between the immunosensor and the ELISA test, providing further evidence of the reliability of the proposed approach. The LOD values for the $\mu \mathrm{PAD}$ and the commercial ELISA kit were 3 and $39 \mathrm{pg} \mathrm{mL}^{-1}$, respectively. Moreover, the precision of the method was evaluated using CD81 standards. The within-assay precision was tested by five measurements on the same day. These analyses were repeated for 3 consecutive days to estimate the between-assay precision. The developed immunosensor showed good precision; the $\mathrm{CV}$ within-assay values were below $3.78 \%$, and the between-assay values were below $6.12 \%$. Besides, a lower analysis time $(20 \mathrm{~min})$ and a wide linear concentration range for both biomarkers were noted for the $\mu \mathrm{PAD}$ (Table 1), compared with the ELISA test.

Additionally, the sensor's stability was also evaluated, and this was accomplished by storing the sensor for 1 month at 4 ${ }^{\circ} \mathrm{C}$. No significant loss of sensitivity (less than $5 \%$ ) was noticed after the storage compared to the response just after 

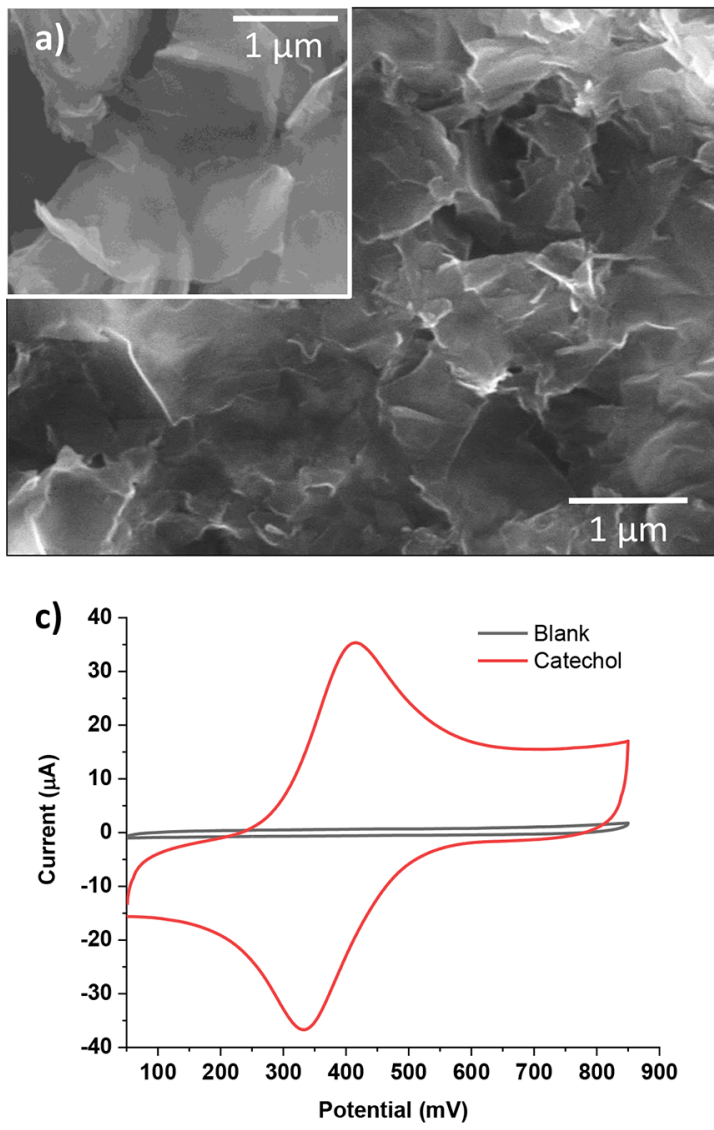

b)
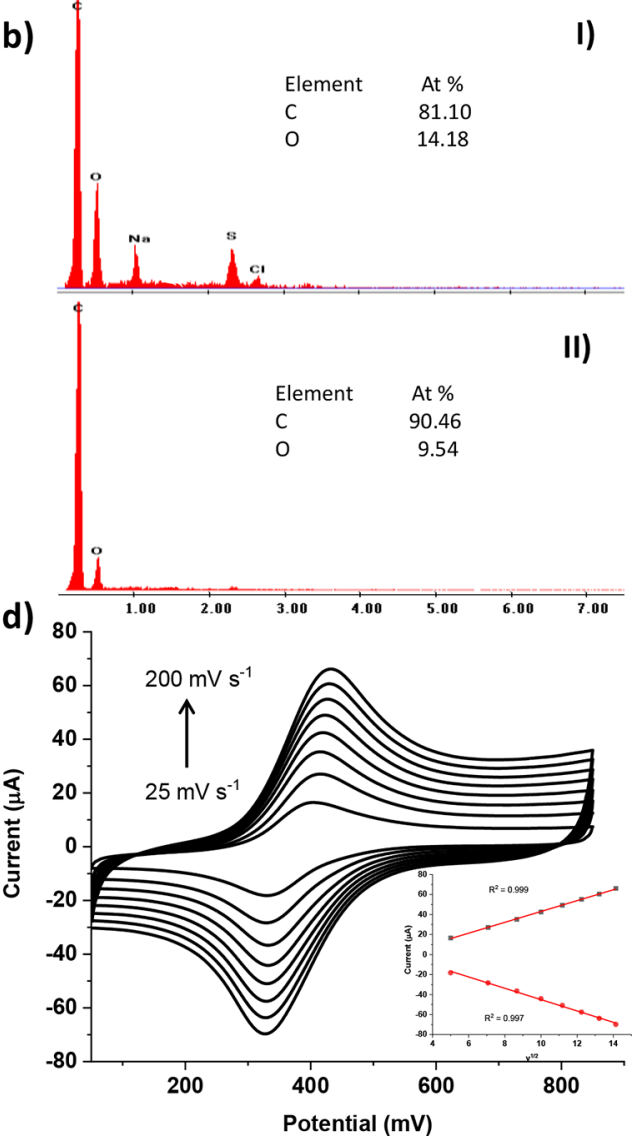

Figure 5. Morphological characterization of the rGO working electrode by SEM (a), energy-dispersive spectra of (I) GO and (II) rGO (b). Cyclic voltammogram recorded with the rGO electrode in $1 \mathrm{mmol} \mathrm{L}^{-1}$ catechol $+0.1 \mathrm{~mol} \mathrm{~L}^{-1}$ phosphate-citrate buffer $\mathrm{pH} 5.00$ at $75 \mathrm{mV} \mathrm{s}{ }^{-1}$ (c), and the plot of the square root of the scan rate on the peak current $(\mathrm{d})$.
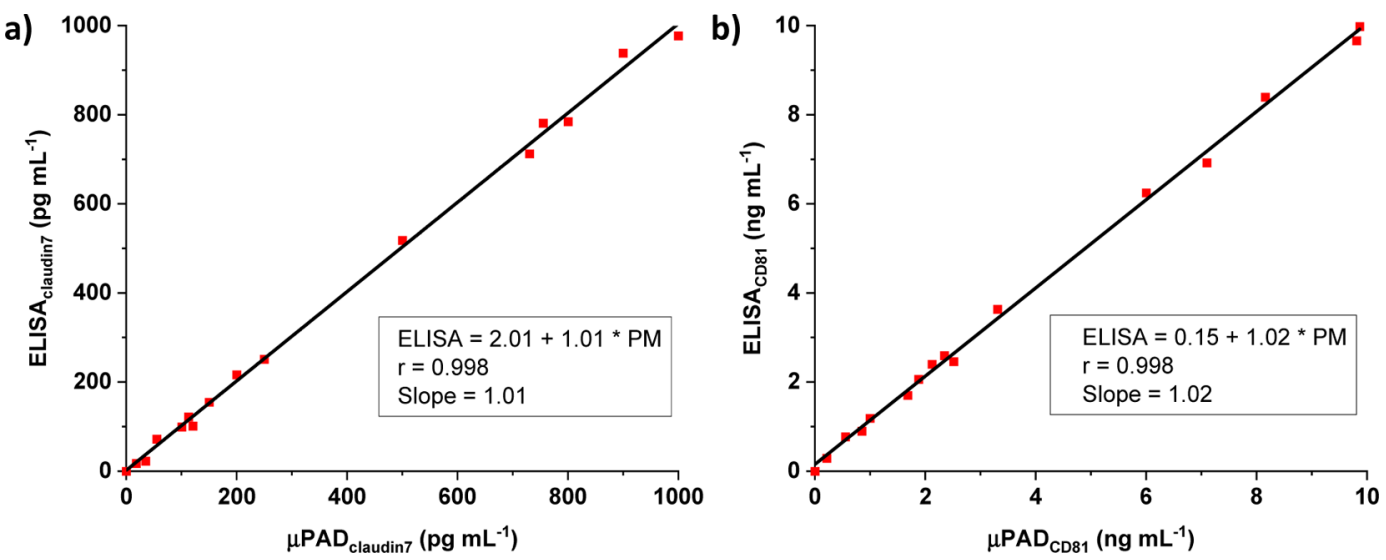

Figure 6. Correlation plot between results obtained with the dual electrochemical paper-based immunosensor and the commercial ELISA kit for Claudin 7 (a) and CD81 (b).

Table 1. Comparison of the Analytical Performance of the Commercial ELISA Kit and the Dual Electrochemical Paper Immunosensor (EI) for Each BC Biomarker

\begin{tabular}{lcccccc}
\multicolumn{1}{c}{ method } & time $(\mathrm{min})$ & $\mathrm{CV} \%^{a}$ within-assay & $\mathrm{CV} \%^{a}$ between-assay & $\mathrm{CV} \%^{a}$ & linear range & LOD \\
ELISA $_{\text {Claudin }}$ & 270 & 6.85 & 9.89 & 7.32 & $15.1-1000^{b}$ & $3.9^{b}$ \\
EI $_{\text {Claudin 7 }}$ & 20 & 3.96 & 6.14 & 3.75 & $2-1000^{b}$ & $0.4^{b}$ \\
ELISA $_{\mathrm{CD} 81}$ & 270 & 4.93 & 8.32 & 6.65 & $0.15-10^{c}$ & $0.039^{c}$ \\
$\mathrm{EI}_{\mathrm{CD} 81}$ & 20 & 3.78 & 6.12 & 3.66 & $0.01-10^{c}$ & $0.003^{c}$
\end{tabular}

${ }^{a}$ Five replicates $(n=5) .{ }^{b} \mathrm{pg} \mathrm{mL}{ }^{-1}$ claudin $7 .{ }^{c} \mathrm{ng} \mathrm{mL}{ }^{-1} \mathrm{CD} 81$. 
a)

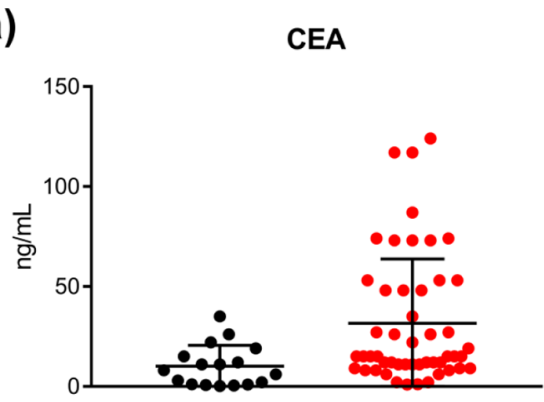

c)

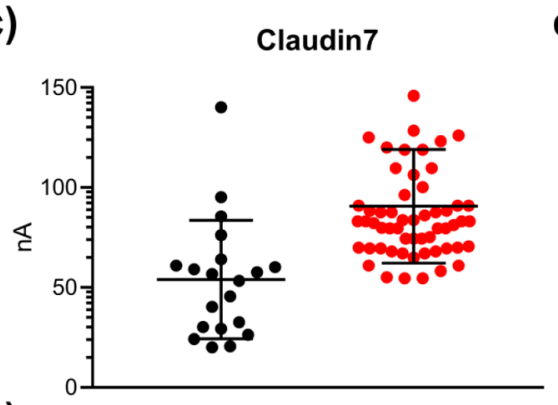

e)

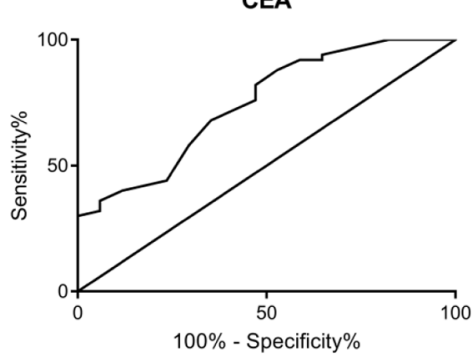

g)

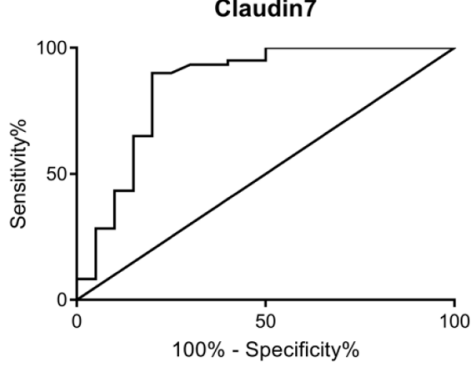

b)

CA 15.3

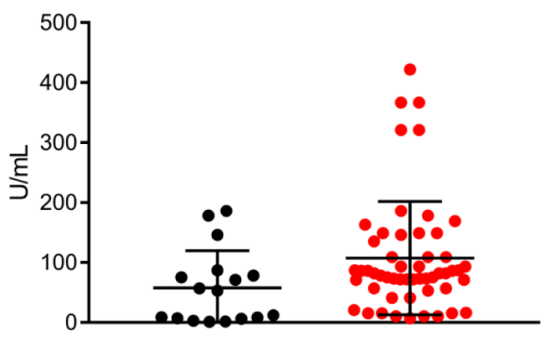

d)

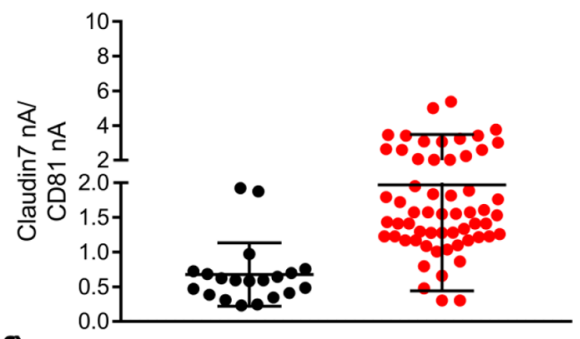

f)

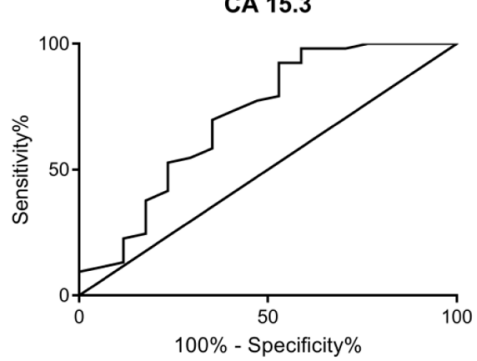

h)

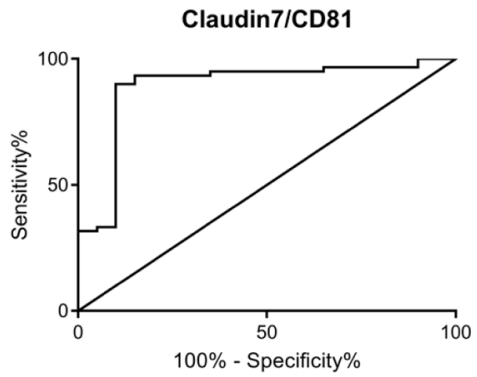

Figure 7. CEA, CA15.3, Claudin 7, and Claudin 7/CD81 levels $(\mathrm{a}-\mathrm{d})$ in plasma in the validation set of patients and healthy volunteers $(n=60$ and $n=20$ respectively). ROC curves of CEA, CA15.3, Claudin 7, and Claudin 7/CD81 ratio $(\mathrm{e}-\mathrm{h})$ for the assessment of diagnosis accuracy of BC.

fabrication. Moreover, the selectivity was investigated against EV samples with other cancer biomarkers such as EPCAM, EGFR, CEA, and CA 15-3 in 10-fold concentrations compared to that of CD81 and Claudin 7. As shown in Supporting Information 10, the presence of these interfering compounds caused negligible changes in the response (less than 2\%). Hence, the results indicated a strong ability of the developed immunosensor to avoid interferences, which is attributed to the use of monoclonal antibodies and the blocking of nonspecific adsorption on the surface. Finally, a comparison of both paper and SBA-15/paper platforms was carried out to assess the effectiveness of using the SBA-15 material. Results shown in the Supporting Information 11 clearly confirm the increased sensitivity obtained with the SBA-15/paper platform owing to the enhanced surface to volume ratio.

Validation of Claudin 7 Determination and Claudin 7/CD81 Ratio. Eighty participants were recruited for validation of the Claudin 7 biomarker: 20 healthy volunteers and $60 \mathrm{BC}$ patients (Figure 1 and Table S1). Values for Claudin 7 and the Claudin $7 / C D 81$ ratio were significantly higher for patients with $\mathrm{BC}[n=60$, Claudin 7 median $83 \mathrm{nA}$, interquartile range (IQR) 69.9-104.8 nA; mean $90.68 \pm 28.4$ $\mathrm{SD}$; Claudin 7/CD81 ratio median $1.55 \mathrm{nA}, \mathrm{IQR} 1.22-2.19$ $\mathrm{nA}$; mean $1.971 \pm 1.58 \mathrm{SD}$ ] compared to those of the healthy control group $(n=20$; Claudin 7 median $55 \mathrm{nA}$, IQR 29.53$63.3 \mathrm{nA}$; mean $0.53 .91 \pm 29.62 \mathrm{SD}$; Claudin $7 / \mathrm{CD} 81$ ratio median 0.594, IQR $0.22-0.71$, mean $0.67 \pm 0.4582$ SD) (Figure 7). These data suggest that Claudin 7 and the Claudin 7/CD81 ratio are excellent biomarkers for early $\mathrm{BC}$ diagnosis.

In addition, levels of Claudin 7 and the Claudin 7/CD81 ratio did not correlate with the tumor's size (for Claudin 7 , Pearson $r=0.058 ; p=0.65$ and for Claudin 7/CD81 ratio, Pearson $r=0.121 ; p=0.35$ ). Moreover, Claudin 7 and the Claudin 7/CD81 ratio levels showed no significant correlation 
Table 2. Correlation between Claudin 7 Determination and Clinical Relevant Data of Enrolled Patients

\begin{tabular}{|c|c|c|c|c|c|c|c|}
\hline & age & menopause status & grade & estrogens receptor & progesterone receptor & Her2 & Ki-67 (\%) \\
\hline \multicolumn{8}{|c|}{ Pearson $r$} \\
\hline Claudin 7 & 0.077 & 0.141 & 0.058 & 0.101 & 0.0646 & 0.133 & 0.017 \\
\hline Claudin 7/CD81 & 0.067 & 0.101 & 0.121 & 0.033 & -0.061 & 0.068 & 0.044 \\
\hline \multicolumn{8}{|c|}{$P$ Values } \\
\hline Claudin 7 & 0.554 & 0.281 & 0.658 & 0.440 & 0.626 & 0.334 & 0.901 \\
\hline Claudin 7/CD81 & 0.610 & 0.439 & 0.356 & 0.802 & 0.645 & 0.621 & 0.749 \\
\hline
\end{tabular}

with age, menopause status, grade, Ki-67, and status of ER, PR, and Her2 $(p>0.05$; Table 2). Similar results were obtained in a previous study, where the Claudin 7 concentration was determined in the tissues of BC patients. ${ }^{40}$

By analysis of ROC curves, an optimum diagnostic cutoff of $95.75 \mathrm{nA}$ was observed for Claudin 7 [area under the curve (AUC), 0.8517; 95\% confidence interval $(\mathrm{CI})=0.732-0.971$; sensitivity at $95 \%$ specificity, $75.13 \%$ ] and an optimum diagnosis cutoff of 0.9885 for the Claudin $7 / \mathrm{CD} 81$ ratio (AUC, 0.8908; 95\% CI $=0.796-0.985$; sensitivity at $90 \%$ specificity, 90\%). In the assessment of differential accuracy, Claudin 7 and the Claudin 7/CD81 ratio showed higher AUC values $(0.8517 \pm 0.06 \mathrm{SD}$ for Claudin 7 and $0.8908 \pm 0.048$ SD for Claudin $7 / \mathrm{CD} 81$ ratio) than classical serum markers as CEA (AUC, $0.5217 \pm 0.068$ SD) and CA 15.3 (AUC, 0.7683 $\pm 0.0056 \mathrm{SD})$. Indeed, as expected, the Claudin $7 / \mathrm{CD} 81$ ratio showed slightly higher accuracy than only Claudin 7 by comparing AUC values (Figure 7).

In this work, we have demonstrated that the identification of tumor specific markers in the total bulk of circulating EVs can be useful to improve $\mathrm{BC}$ diagnosis. ${ }^{41} \mathrm{EV}$ s contain diseaseassociated proteins and transport important information from the cells of origin. ${ }^{42}$ The characterization of plasma-isolated EVs has two important advantages compared to circulating biomarkers in total plasma. First, lipid membranes of EVs protect their cargo from proteases. Moreover, a reduction in the proteome complexity of the biological fluids is expected when EVs are isolated by SEC. ${ }^{43}$ Additionally, RPPA analysis of EVs has been a remarkable tool to identify specifically EVs associated with cancer biomarkers with excellent sensitivity. The focus was directed toward specific markers of epithelial tissue, but such proteomic studies can identify other biomarkers. Recently, in agreement with our work, Claudin 7 has been identified as a diagnostic marker in serum from colon cancer patients. ${ }^{44}$ In the last years, new diagnostic methodologies and the improvement of primary antibodies have facilitated identifying new proteins as a diagnostic marker. In our case, thanks to the employed nanomaterials, we developed a dual immunosensor with excellent sensitivity to determine both Claudin 7 and CD81. The use of paper and graphite as materials for chip fabrication reduces economic cost. This kind of chips has multiple advantages such as affordability, facile disposability, portability, and simple fabrication, facilitating mass production. ${ }^{23,28}$ Moreover, multiplexing these devices enables the simultaneous execution of multiple assays on a single device without cross-contamination. ${ }^{16}$ In our work, we employed this dual paper chip in a validation set of 60 patients, and we demonstrated that Claudin 7 and the Claudin 7/CD81 ratio can drastically improve the early $\mathrm{BC}$ diagnosis compared with classical markers used in standard methodologies. Besides, the normalization with CD81 guarantees that Claudin 7 variations are due to the number of epithelial EVs and not caused by a change in the number of total EVs. ${ }^{45}$ We did not observe any other relation with the clinical outcomes of patients and Claudin 7 determination in EVs. Curiously, the release of Claudin 7 in EVs did not correlate with tumor size, possibly because the size differences were not large enough. Another possible explanation is that Claudin 7 is a protein involved in focal adhesion, and its release is more related to cellular reorganization than in cellular growth. ${ }^{46,47}$ In any case, this marker should be validated in a higher number of patients, different stages of the disease as locally invasive or metastatic $\mathrm{BC}$, and/or other diseases that could be related with false positives. Besides, this methodology must be validated by in vitro and in vivo models or risk population screening to predict $\mathrm{BC}$ earlier. At the moment, we can say that this analysis is highly specific, highly sensitive, simple, and cheap. Future studies must demonstrate prognostic and predictive value as well as suitability as a monitoring tool.

\section{CONCLUSIONS}

Based on the results of this study, we demonstrated the following: (i) circulating EVs represent a valuable sample to be used in early diagnosis of BC. (ii) Claudin 7 has been identified as the most significant epithelial protein expressed in EVs and validated as a BC diagnosis marker. (iii) CD81 is a suitable normalizer of $\mathrm{EV}$ markers in plasma, improving the accuracy of Claudin7 for BC diagnosis. (iv) Both Claudin 7 and Claudin 7/CD81 ratio have better accuracy than classical circulating markers as CEA and CA 15.3 for early diagnosis of BC.

We also demonstrated that our dual sandwich-type electrochemical paper-based immunosensor has a shorter overall assay time $(20 \mathrm{~min})$ than the one usually employed in the commercial ELISA test kits $(270 \mathrm{~min})$ for both biomarkers, with no reduction on the sensitivity and specificity. Finally, the paper-based immunosensor demonstrated to be highly specific (due to the use of monoclonal antibodies), sensitive (10-fold for Claudin 7 and 13-fold for CD81 in comparison with their respective ELISA test), simple, and cheap (12 times cheaper than the ELISA test), improving significantly the accuracy of early diagnosis of $\mathrm{BC}$.

\section{ASSOCIATED CONTENT}

\section{SI Supporting Information}

The Supporting Information is available free of charge at https://pubs.acs.org/doi/10.1021/acs.analchem.0c04180.

Experimental section, EV characterization procedure, RPPA process, GO synthesis, GO ink preparation, synthesis and amino functionalization of SBA-15, correlation of CD81 vs RPPA normalizer, optimization of experimental parameters, calibration curves of the immunosensor, selectivity study against other cancer biomarkers, and saturation test for peroxidase immobilization (PDF) 


\section{AUTHOR INFORMATION}

\section{Corresponding Authors}

Matías D. Regiart - LSEME, Laboratório de Sensores Eletroquímicos e Métodos Eletroanalíticos. Department of Fundamental Chemistry, Institute of Chemistry, University of São Paulo, 05513-970 São Paulo, São Paulo, Brazil; Email: matiasregiart@gmail.com

Martín A. Fernández-Baldo - INQUISAL, Departamento de Química, Universidad Nacional de San Luis, D5700BWS San Luis, Argentina; 10 orcid.org/0000-0003-0385-2391; Email: mbaldo@unsl.edu.ar

\section{Authors}

Francisco G. Ortega - Balearic Islands Health Research Institute (IdISBa), 07010 Palma de Mallorca, Spain

Alba Rodríguez-Martínez - Liquid Biopsy and Metastasis Research Group, GENYO, Centre for Genomics and Oncological Research: Pfizer and Laboratory of Genetic Identification, Legal Medicine and Toxicology Department, Faculty of Medicine-PTS, University of Granada, 18016 Granada, Spain

Diego de Miguel-Pérez - Liquid Biopsy and Metastasis Research Group, GENYO, Centre for Genomics and Oncological Research: Pfizer, University of Granada, 18016 Granada, Spain

María J. Serrano - Liquid Biopsy and Metastasis Research Group, GENYO, Centre for Genomics and Oncological Research: Pfizer, University of Granada, 18016 Granada, Spain

José A. Lorente - Liquid Biopsy and Metastasis Research Group, GENYO, Centre for Genomics and Oncological Research: Pfizer and Laboratory of Genetic Identification, Legal Medicine and Toxicology Department, Faculty of Medicine-PTS, University of Granada, 18016 Granada, Spain

Gonzalo Tortella - Departamento de Ingeniería Química, Universidad de La Frontera, 4811230 Temuco, Chile; Centro de Excelencia en Investigación Biotecnológica Aplicada al Medio Ambiente (CIBAMA), 4811230 Temuco, Chile

Olga Rubilar - Departamento de Ingeniería Química, Universidad de La Frontera, 4811230 Temuco, Chile; Centro de Excelencia en Investigación Biotecnológica Aplicada al Medio Ambiente (CIBAMA), 4811230 Temuco, Chile

Karim Sapag - INFAP, Laboratorio de Solidos Porosos, Universidad Nacional de San Luis, D5700BWS San Luis, Argentina

Mauro Bertotti - LSEME, Laboratório de Sensores Eletroquímicos e Métodos Eletroanalíticos. Department of Fundamental Chemistry, Institute of Chemistry, University of São Paulo, 05513-970 São Paulo, São Paulo, Brazil

Complete contact information is available at:

https://pubs.acs.org/10.1021/acs.analchem.0c04180

\section{Notes}

The authors declare no competing financial interest.

\section{ACKNOWLEDGMENTS}

Support from Universidad Nacional de San Luis (PROICO 22/Q241), from the Agencia Nacional de Promoción Cientifica y Tecnológica (PICT 2018-04443, PICT-20152246, PICT-2015-1575, PICT-2014-1184 and PICT-20140375), from Consejo Nacional de Investigaciones Científicas y
Técnicas (CONICET) (Argentina) (PIP $11220150100004 \mathrm{CO})$, from GENYO, Centre for Genomics and Oncological Research: Pfizer-University of Granada, Andalusian Regional Government (Granada, Spain), and the Fundação de Amparo à Pesquisa do Estado de São Paulo (FAPESP) (2019/06293-6 and 2018/08782-1) is acknowledged.

\section{REFERENCES}

(1) Bray, F.; Ferlay, J.; Soerjomataram, I.; Siegel, R. L.; Torre, L. A.; Jemal, A. Ca-Cancer J. Clin. 2018, 68, 394-424.

(2) Harbeck, N.; Gnant, M. Lancet 2017, 389, 1134-1150.

(3) Nothacker, M.; Duda, V.; Hahn, M.; Warm, M.; Degenhardt, F.; Madjar, H.; Weinbrenner, S.; Albert, U. S. BMC Cancer 2009, 9, 335.

(4) Kazarian, A.; Blyuss, O.; Metodieva, G.; Gentry-Maharaj, A.; Ryan, A.; Kiseleva, E. M.; Prytomanova, O. M.; Jacobs, I. J.; Widschwendter, M.; Menon, U.; Timms, J. F. Br. J. Cancer 2017, 116, 501-508.

(5) Perakis, S.; Speicher, M. R. BMC Med. 2017, 15, 75.

(6) Pang, B.; Zhu, Y.; Ni, J.; Thompson, J.; Malouf, D.; Bucci, J.; Graham, P.; Li, Y. Theranostics 2020, 10, 2309-2326.

(7) Simpson, R. J.; Lim, J. W.; Moritz, R. L.; Mathivanan, S. Expert Rev. Proteomics 2009, 6, 267-283.

(8) Shao, C.; Yang, F.; Miao, S.; Liu, W.; Wang, C.; Shu, Y.; Shen, H. Mol. Canc. 2018, 17, 120.

(9) Ortega, F. G.; Roefs, M. T.; de Miguel Perez, D.; Kooijmans, S. A.; de Jong, O. G.; Schiffelers, R. M.; Vader, P.; Vader, P. Nanomed. Nanotechnol. Biol. Med. 2019, 20, 102014.

(10) Marrugo-Ramírez, J.; Mir, M.; Samitier, J. Int. J. Mol. Sci. 2018, 19, 2877.

(11) Chikkaveeraiah, B. V.; Bhirde, A. A.; Morgan, N. Y.; Eden, H. S.; Chen, X. ACS Nano 2012, 6, 6546-6561.

(12) Li, H.; He, J.; Li, S.; Turner, A. P. F. Biosens. Bioelectron. 2013, $43,25-29$.

(13) Shiddiky, M. J. A.; Rauf, S.; Kithva, P. H.; Trau, M. Biosens. Bioelectron. 2012, 35, 251-257.

(14) Zhu, C.; Yang, G.; Li, H.; Du, D.; Lin, Y. Anal. Chem. 2015, 87, 230-249.

(15) Lin, Y.; Liu, K.; Wang, C.; Li, L.; Liu, Y. Anal. Chem. 2015, 87, $8047-8051$

(16) Jones, A.; Dhanapala, L.; Kankanamage, R. N. T.; Kumar, C. V.; Rusling, J. F. Anal. Chem. 2019, 92, 345.

(17) Li, Y.; Liu, W.; Jin, G.; Niu, Y.; Chen, Y.; Xie, M. Anal. Chem. 2018, 90, 8002-8010.

(18) Scida, K.; Cunningham, J. C.; Renault, C.; Richards, I.; Crooks, R. M. Anal. Chem. 2014, 86, 6501-6507.

(19) Wang, C.-C.; Hennek, J. W.; Ainla, A.; Kumar, A. A.; Lan, W.J.; Im, J.; Smith, B. S.; Zhao, M.; Whitesides, G. M. Anal. Chem. 2016, $88,6326-6333$.

(20) Adkins, J. A.; Boehle, K.; Friend, C.; Chamberlain, B.; Bisha, B.; Henry, C. S. Anal. Chem. 2017, 89, 3613-3621.

(21) Arduini, F.; Cinti, S.; Caratelli, V.; Amendola, L.; Palleschi, G.; Moscone, D. Biosens. Bioelectron. 2019, 126, 346-354.

(22) Cincotto, F. H.; Fava, E. L.; Moraes, F. C.; Fatibello-Filho, O.; Faria, R. C. Talanta 2019, 195, 62-68.

(23) Noviana, E.; McCord, C. P.; Clark, K. M.; Jang, I.; Henry, C. S. Lab Chip 2020, 20, 9-34.

(24) Han, Z.; Shu, J.; Jiang, Q.; Cui, H. Anal. Chem. 2018, 90, 6064-6070.

(25) Campu, A.; Lerouge, F.; Chateau, D.; Chaput, F.; Baldeck, P.; Parola, S.; Maniu, D.; Craciun, A. M.; Vulpoi, A.; Astilean, S.; Focsan, M. Anal. Chem. 2018, 90, 8567-8575.

(26) Dybowska-Sarapuk, L.; Kielbasinski, K.; Arazna, A.; Futera, K.; Skalski, A.; Janczak, D.; Sloma, M.; Jakubowska, M. Nanomaterials 2018, 8, 602 .

(27) Dos Santos, S. M. L.; Nogueira, K. A. B.; De Souza Gama, M.; Lima, J. D. F.; da Silva Júnior, I. J.; De Azevedo, D. C. S. Microporous Mesoporous Mater. 2013, 180, 284-292. 
(28) Sun, X.; Li, B.; Tian, C.; Yu, F.; Zhou, N.; Zhan, Y.; Chen, L. Anal. Chim. Acta 2018, 1007, 33-39.

(29) Wang, H.; Zhou, C.; Sun, X.; Jian, Y.; Kong, Q.; Cui, K.; Ge, S.; $\mathrm{Yu}, \mathrm{J}$. Biosens. Bioelectron. 2018, 117, 651-658.

(30) Wei, B.; Mao, K.; Liu, N.; Zhang, M.; Yang, Z. Biosens. Bioelectron. 2018, 121, 41-46.

(31) Théry, C.; Witwer, K. W.; Aikawa, E.; Alcaraz, M. J.; Anderson, J. D.; Andriantsitohaina, R.; Antoniou, A.; Arab, T.; Archer, F.; AtkinSmith, G. K.; Ayre, D. C.; Bach, J. M.; Bachurski, D.; Baharvand, H.; Balaj, L.; Baldacchino, S.; Bauer, N. N.; Baxter, A. A.; Bebawy, M.; Beckham, C.; Bedina Zavec, A.; Benmoussa, A.; Berardi, A. C.; Bergese, P.; Bielska, E.; Blenkiron, C.; Bobis-Wozowicz, S.; Boilard, E.; Boireau, W.; Bongiovanni, A.; Borràs, F. E.; Bosch, S.; Boulanger, C. M.; Breakefield, X.; Breglio, A. M.; Brennan, M.; Brigstock, D. R.; Brisson, A.; Broekman, M. L. D.; Bromberg, J. F.; Bryl-Górecka, P.; Buch, S.; Buck, A. H.; Burger, D.; Busatto, S.; Buschmann, D.; Bussolati, B.; Buzás, E. I.; Byrd, J. B.; Camussi, G.; Carter, D. R. F.; Caruso, S.; Chamley, L. W.; Chang, Y. T.; Chaudhuri, A. D.; Chen, C.; Chen, S.; Cheng, L.; Chin, A. R.; Clayton, A.; Clerici, S. P.; Cocks, A.; Cocucci, E.; Coffey, R. J.; Cordeiro-da-Silva, A.; Couch, Y.; Coumans, F. A. W.; Coyle, B.; Crescitelli, R.; Criado, M. F.; D’SouzaSchorey, C.; Das, S.; de Candia, P.; De Santana, E. F.; De Wever, O.; del Portillo, H. A.; Demaret, T.; Deville, S.; Devitt, A.; Dhondt, B.; Di Vizio, D.; Dieterich, L. C.; Dolo, V.; Dominguez Rubio, A. P.; Dominici, M.; Dourado, M. R.; Driedonks, T. A. P.; Duarte, F. V.; Duncan, H. M.; Eichenberger, R. M.; Ekström, K.; EL Andaloussi, S.; Elie-Caille, C.; Erdbrügger, U.; Falcón-Pérez, J. M.; Fatima, F.; Fish, J. E.; Flores-Bellver, M.; Försönits, A.; Frelet-Barrand, A.; Fricke, F.; Fuhrmann, G.; Gabrielsson, S.; Gámez-Valero, A.; Gardiner, C.; Gärtner, K.; Gaudin, R.; Gho, Y. S.; Giebel, B.; Gilbert, C.; Gimona, M.; Giusti, I.; Goberdhan, D. C. I.; Görgens, A.; Gorski, S. M.; Greening, D. W.; Gross, J. C.; Gualerzi, A.; Gupta, G. N.; Gustafson, D.; Handberg, A.; Haraszti, R. A.; Harrison, P.; Hegyesi, H.; Hendrix, A.; Hill, A. F.; Hochberg, F. H.; Hoffmann, K. F.; Holder, B.; Holthofer, H.; Hosseinkhani, B.; Hu, G.; Huang, Y.; Huber, V.; Hunt, S.; Ibrahim, A. G. E.; Ikezu, T.; Inal, J. M.; Isin, M.; Ivanova, A.; Jackson, H. K.; Jacobsen, S.; Jay, S. M.; Jayachandran, M.; Jenster, G.; Jiang, L.; Johnson, S. M.; Jones, J. C.; Jong, A.; Jovanovic-Talisman, T.; Jung, S.; Kalluri, R.; Kano, S.; Kaur, S.; Kawamura, Y.; Keller, E. T.; Khamari, D.; Khomyakova, E.; Khvorova, A.; Kierulf, P.; Kim, K. P.; Kislinger, T.; Klingeborn, M.; Klinke, D. J.; Kornek, M.; Kosanović, M. M.; Kovács, Á. F.; Krämer-Albers, E. M.; Krasemann, S.; Krause, M.; Kurochkin, I. V.; Kusuma, G. D.; Kuypers, S.; Laitinen, S.; Langevin, S. M.; Languino, L. R.; Lannigan, J.; Lässer, C.; Laurent, L. C.; Lavieu, G.; Lázaro-Ibáñez, E.; Le Lay, S.; Lee, M. S.; Lee, Y. X. F.; Lemos, D. S.; Lenassi, M.; Leszczynska, A.; Li, I. T. S.; Liao, K.; Libregts, S. F.; Ligeti, E.; Lim, R.; Lim, S. K.; Line, A.; Linnemannstöns, K.; Llorente, A.; Lombard, C. A.; Lorenowicz, M. J.; Lörincz, Á. M.; Lötvall, J.; Lovett, J.; Lowry, M. C.; Loyer, X.; Lu, Q.; Lukomska, B.; Lunavat, T. R.; Maas, S. L. N.; Malhi, H.; Marcilla, A.; Mariani, J.; Mariscal, J.; Martens-Uzunova, E. S.; Martin-Jaular, L.; Martinez, M. C.; Martins, V. R.; Mathieu, M.; Mathivanan, S.; Maugeri, M.; McGinnis, L. K.; McVey, M. J.; Meckes, D. G.; Meehan, K. L.; Mertens, I.; Minciacchi, V. R.; Möller, A.; Møller Jørgensen, M.; Morales-Kastresana, A.; Morhayim, J.; Mullier, F.; Muraca, M.; Musante, L.; Mussack, V.; Muth, D. C.; Myburgh, K. H.; Najrana, T.; Nawaz, M.; Nazarenko, I.; Nejsum, P.; Neri, C.; Neri, T.; Nieuwland, R.; Nimrichter, L.; Nolan, J. P.; Nolte-'t Hoen, E. N. M.; Noren Hooten, N.; O’Driscoll, L.; O’Grady, T.; O’Loghlen, A.; Ochiya, T.; Olivier, M.; Ortiz, A.; Ortiz, L. A.; Osteikoetxea, X.; Ostegaard, O.; Ostrowski, M.; Park, J.; Pegtel, D. M.; Peinado, H.; Perut, F.; Pfaffl, M. W.; Phinney, D. G.; Pieters, B. C. H.; Pink, R. C.; Pisetsky, D. S.; Pogge von Strandmann, E.; Polakovicova, I.; Poon, I. K. H.; Powell, B. H.; Prada, I.; Pulliam, L.; Quesenberry, P.; Radeghieri, A.; Raffai, R. L.; Raimondo, S.; Rak, J.; Ramirez, M. I.; Raposo, G.; Rayyan, M. S.; Regev-Rudzki, N.; Ricklefs, F. L.; Robbins, P. D.; Roberts, D. D.; Rodrigues, S. C.; Rohde, E.; Rome, S.; Rouschop, K. M. A.; Rughetti, A.; Russell, A. E.; Saá, P.; Sahoo, S.; Salas-Huenuleo, E.; Sánchez, C.; Saugstad, J. A.; Saul, M. J.; Schiffelers, R. M.; Schneider, R.; Schøyen,
T. H.; Scott, A.; Shahaj, E.; Sharma, S.; Shatnyeva, O.; Shekari, F.; Shelke, G. V.; Shetty, A. K.; Shiba, K.; Siljander, P. R. M.; Silva, A. M.; Skowronek, A.; Snyder, O. L.; Soares, R. P.; Sódar, B. W.; Soekmadji, C.; Sotillo, J.; Stahl, P. D.; Stoorvogel, W.; Stott, S. L.; Strasser, E. F.; Swift, S.; Tahara, H.; Tewari, M.; Timms, K.; Tiwari, S.; Tixeira, R.; Tkach, M.; Toh, W. S.; Tomasini, R.; Torrecilhas, A. C.; Tosar, J. P.; Toxavidis, V.; Urbanelli, L.; Vader, P.; van Balkom, B. W. M.; van der Grein, S. G.; Van Deun, J.; van Herwijnen, M. J. C.; Van KeurenJensen, K.; van Niel, G.; van Royen, M. E.; van Wijnen, A. J.; Vasconcelos, M. H.; Vechetti, I. J.; Veit, T. D.; Vella, L. J.; Velo, E.; Verweij, F. J.; Vestad, B.; Viñas, J. L.; Visnovitz, T.; Vukman, K. V.; Wahlgren, J.; Watson, D. C.; Wauben, M. H. M.; Weaver, A.; Webber, J. P.; Weber, V.; Wehman, A. M.; Weiss, D. J.; Welsh, J. A.; Wendt, S.; Wheelock, A. M.; Wiener, Z.; Witte, L.; Wolfram, J.; Xagorari, A.; Xander, P.; Xu, J.; Yan, X.; Yáñez-Mó, M.; Yin, H.; Yuana, Y.; Zappulli, V.; Zarubova, J.; Žekas, V.; Zhang, J.; Zhao, Z.; Zheng, L.; Zheutlin, A. R.; Zickler, A. M.; Zimmermann, P.; Zivkovic, A. M.; Zocco, D.; Zuba-Surma, E. K. J. Extracell. Vesicles 2018, 7, 1535750.

(32) Mahmood, T.; Yang, P. C. N. Am. J. Med. Sci. 2012, 4, 429434.

(33) Siwak, D. R.; Li, J.; Akbani, R.; Liang, H.; Lu, Y. Adv. Exp. Med. Biol. 2019, 1188, 113-147.

(34) Hummers, W., Jr.; Offeman, R. J. Am. Chem. Soc. 1958, 80, 1393.

(35) Ambrosi, A.; Bonanni, A.; Sofer, Z.; Cross, J. S.; Pumera, M. Chem.-Eur. J. 2011, 17, 10763-10770.

(36) Zhao, M.; Li, H.; Liu, W.; Guo, Y.; Chu, W. Biosens. Bioelectron. 2016, 79, 581-588.

(37) Regiart, M.; Magallanes, J. L.; Barrera, D.; Villarroel-Rocha, J.; Sapag, K.; Raba, J.; Bertolino, F. A. Sens. Actuators, B 2016, 232, 765772 .

(38) Regiart, M.; Fernández-Baldo, M. A.; Villarroel-Rocha, J.; Messina, G. A.; Bertolino, F. A.; Sapag, K.; Timperman, A. T.; Raba, J. Anal. Chim. Acta 2017, 963, 83-92.

(39) Bard, A. J.; Faulkner, L. R. Electrochemical Methods Fundamentals and Applications, 2nd ed.; John Wiley\&Sons: New Jersey, USA, 2001.

(40) Logullo, A. F.; Pasini, F.; Nonogaki, S.; Rocha, R.; Soares, F.; Brentani, M. Mol. Clin. Oncol. 2018, 9, 377.

(41) Rahbarghazi, R.; Jabbari, N.; Sani, N. A.; Asghari, R.; Salimi, L.; Kalashani, S. A.; Feghhi, M.; Etemadi, T.; Akbariazar, E.; Mahmoudi, M.; Rezaie, J. Cell Commun. Signal. 2019, 17, 73.

(42) Rosa-Fernandes, L.; Rocha, V. B.; Carregari, V. C.; Urbani, A.; Palmisano, G. Front. Chem. 2017, 5, 102.

(43) de Miguel Pérez, D.; Rodriguez Martínez, A.; Ortigosa Palomo, A.; Delgado Ureña, M.; Garcia Puche, J. L.; Robles Remacho, A.; Exposito Hernandez, J.; Lorente Acosta, J. A.; Ortega Sánchez, F. G.; Serrano, M. J. Sci. Rep. 2020, 10, 3974.

(44) Xu, C.; Wang, X.; Li, W.; Wang, K.; Ding, L. Technol. Canc. Res. Treat. 2018, 17, 1533033818817774.

(45) Kowal, J.; Arras, G.; Colombo, M.; Jouve, M.; Morath, J. P.; Primdal-Bengtson, B.; Dingli, F.; Loew, D.; Tkach, M.; Théry, C. Proc. Natl. Acad. Sci. U.S.A. 2016, 113, E968-E977.

(46) Wang, K.; Xu, C.; Li, W.; Ding, L. Cancer Manage. Res. 2018, 10, 3741-3752.

(47) Singh, A. B.; Dhawan, P. Semin. Cell Dev. Biol. 2015, 42, 58-65. 